switches, and motors, are fitted with the safety devices suggested by research, and are tested in explosive atmospheres composed of firedamp and air in the proportions which give the most stringent test in the circumstances. For underground signalling by bells and telephones, the design of electric circuits has been so improved as to render the spark at break unable to ignite firedamp.

An extensive investigation of the danger of friction sparks from picks and coal cutters, and of electric sparks due to the spontaneous generation of electricity in a cloud of coal dust, is approaching completion.

Electrical Researches.-Apart from the investigations named above, the chief object of the electrical researches in the new laboratories will be to improve the safety of the electrical equipment necessary for increased illumination of the mine; for better illumination will not only enable the collier to avoid many accidents, but also will, it is believed, prevent the eye disease called miners' nystagmus.

Mining Explosives. The official safety test for mining explosives was designed to be more severe than the conditions of the pit, but explosives which have passed the test have proved not to be safe in all circumstances. It seems impossible, at the moment, to propose any improvement on the test, for want of exact knowledge of the mode of ignition of gas by an explosive. The subject is under investigation by the Board, but the work has been mainly transferred to the Buxton station.

Safety Lamps.-Flame safety lamps have been studied in detail during recent years, and much improved illumination obtained by suitable modifications. in design and suitable blendings of lamp oils. The results of these researches are in the hands of manufacturers, and experimental lamps are receiving trial underground.

Mine-Rescue Apparatus.-Self-contained breathing apparatus provides a supply of oxygen independent of the atmosphere, and is necessarily somewhat heavy and cumbrous. It may frequently happen that a suitable gas mask could be substituted, and attempts are being made to produce one which contains sufficient absorbents to remove all noxious gases, including carbon monoxide, and yet not to offer so much resistance to the passage of air that the wearer is hampered. A study of carbon monoxide estimators, and the construction of a portable oxygen estimator, are also contemplated.

\title{
The University of Leeds.
}

\section{Extension of the Textile Industries Departinent.}

$\mathrm{O}^{\mathrm{N}}$ Thursday, Oct. 12, the Master of the Worshipful Company of Clothworkers of the City of London opened the new extension of the Clothworkers' Departments of the University of Leeds, the buildings of which have cost approximately $£ 12,000$, and the equipment, largely provided by donors in the textile industry, another $£ 10,000$. The extension has been designed to facilitate (1) the installation of an experimental wool plant covering all the processes for the woollen and worsted industries ; $(2)$ the extension of museum and laboratory accommodation to fulfil the requirements of a much larger number of postgraduate and degree students attending the department; and (3) to provide additional accommodation for the Sill Research Association which is housed within the University precincts.

It is fifty-four years since the Clothworkers' Company gave the first donation which enabled the Textile Industries Department to be installed alongside the Science Departments in the then Yorkshire College of Science. Largely owing to the traditional character of the wool industries and the complexity of the wool fibre and wool processes, the bearings of science upon the technology of the subject have not vet been completely realised, but an additional grant from the Clothworkers' Company of $£ 4000$ a year has made it possible to appoint, within the Department of 'Textile Industries, a science staff which, working along with the technological staff, is already showing promise of that association between science and technology which was the primary object of the Clothworkers' Company.

The complete equipments in the woollen and worsted manufacturing processes will enable the technological staff to define clearly miny of the fundamental problems of the industry which in normal practice are hidden owing to a conglomeration of varying factors; and then, with the more refined 'tools' now available, the scientific worker is at hand either to solve the problems in question or to suggest the scientific tools which will help the technologist towards more perfect methods of manufacturing.

At the opening ceremony the Master was supported by a large gathering of representatives from the whole of the woollen and worsted industries and by other supporters of university developments in Yorkshire. The Pro-Chancellor of the University of Leeds, in introducing the Master, gave a history of the association of the Clothworkers with the University, which showed that grants of $£ 100,000$ for accommodation and equipment and $£ 165,000$ for maintenance had already been made, and that in addition to these a grant of $£ 4000$ a year had been raised to $£ 7000$ a year.

The Master, in declaring the buildings open, spoke of the intense interest the Clothworkers' Company takes in the extension of their departments of the University, and expressed his appreciation that the generosity of the Company has met with such a hearty response from the machine makers of Yorkshire and elsewhere. He congratulated the University on the progress it is making, and hoped that the present scheme would fulfil the anticipations of its promoters. The Vice-Chancellor, Dr. J. B. Baillie, and the chairman of the Advisory Committee, Mr. A. Michael Lupton, thanked the Clothworkers for their munificence, and the latter, in seconding the vote of thanks, emphasised the large amount of graduate and post-graduate work which is now being undertaken in these departments. Prof. A. F. Barker, on behalf of the staffs of the departments, and Mr. George Blackburn, on behalf of the past and present students of the departments, also supported the vote of thanks. The architect, Mr. Waterhouse, presented the Master with a key of the building, and the guests then made a tour of inspection.

In the equipment it is interesting to note the comprehensive display of such things as electric driving and lighting, air conditioning, floors and other matters appertaining to recent developments in factory construction and running. In other respects the equip. ments are representative of the latest practice, and almost without exception the firms involved have agreed to keep this equipment thoroughly up-todate. Thus, not only will the equipment be used for teaching purposes, but also for experimental purposes on lines which will make a very strong appeal to those who are endeavouring to keep the textile industries of Great Britain well ahead in all manufacturing processes.

No. 3077, VoL. 122] 